\title{
\&S Research Square \\ Application of Digital Twins to Flexible Production Management: Taking a Shandong Factory as an
}

Example

\section{Wenxue Ran}

Yunnan University of Finance and Economics

Yimin Hu ( $\nabla$ huyimin1998@163.com)

Yunnan University of Finance and Economics https://orcid.org/0000-0003-3375-4346

\section{Yang Zhi}

Yunnan Celan Technology Co.,LTD

\section{Research Article}

Keywords: Digital twin, 3D Visualization, Virtual reality system, Flexible production management

Posted Date: January 13th, 2022

DOl: https://doi.org/10.21203/rs.3.rs-1232905/v1

License: (c) (1) This work is licensed under a Creative Commons Attribution 4.0 International License.

Read Full License 


\section{Abstract}

By enabling the merging of the virtual and real worlds, DT (Digital Twin) technology has considerably aided the development of businesses at both levels of digitization and networking in recent years. As an outcome, industrial research has shifted its attention to this new technology in the manufacturing business. However, there are still technical issues with DT technology, such as real-time data interaction, high integration of constituent elements, and high simulation. This paper proposes to solve these issues by presenting a framework that blends DT with 3D visualization technologies. A case study of an intelligent logistics management 3D scheduling system for a factory in Shandong verifies the applicability of digital twins to flexible production management. The example demonstrates that the framework can be synchronizing the virtual and real systems. Moreover, the framework can effectively cover the whole manufacturing life cycle, enhance production efficiency and product quality, and achieve flexible production management, helping the manufacturing industry's digital and intelligent transition.

\section{Introduction}

Since Michael Grieves initially proposed the DT (Digital Twin) concept in 2002, academics have defined DT from many perspectives (Barricelli et al. 2019). In general, DT has more added value and can serve many areas owing to the background of the loT (Internet of Things), big data, and Industry 4.0(Souza et al. 2019; Kaur et al. 2020). The DT allows for real-time transparency of critical logistical data by combining the virtual and physical worlds (Bolton et al. 2018; Burgos et al. 2021). Second, by monitoring the production process and analyzing data in real-time, a DT can help create efficient production management, other than just simulation (Madni et al. 2019; Lu Y et al. and Liu Q et al. 2020). Furthermore, early simulation is not only costly but also time-consuming in terms of equipment debugging and post-maintenance (Stojanovic $\mathrm{N}$ et al., 2018). In these two aspects, however, DTs outperform early simulations (Ayani et al. 2018). In conclusion, the DT will be critical in an all digitalized product life cycle (Haag et al. and Macchi 2018).

DT technology has played a role in promoting the digital transformation (Anderl R et al. 2018) of the Manufacturing (Liu S et al. 2021), Health Care (Bruynseels et al. 2018; Barricelli et al. 2020), Education (Toivonen et al. 2018). For this reason, DT has become the center of attention in industry and academia in recent years (Fuller et al. 2020; Rasheed et al. 2019). Furthermore, the investment cycle in DTs will reduce by $30 \%$ in the next several years (Shao G et al. 2019). Several large companies, such as General Electric, Siemens, PTC, Dassault Systèmes, and Tesla, are applying DT to improve product performance, manufacturing, production management flexibility, and competitiveness (Tao F et al. 2019). DTs are quickly becoming an essential aspect of digital transformation, and their potential impact is enormous (Saracco et al. 2019). Thus practical application research on DTs is already underway.

In recent academic research, DT technology applying to virtual testing, production control, process optimization, and equipment maintenance in the engineering industry (Wright et al. 2020). However, only $18 \%$ of studies have data transfer in both directions (Kritzinger W et al. 2018). That is because DTs will 
have some challenges in practical applications as follows: (1) The rate of information exchange in realtime is low (Bao J et al. 2019; Putz et al. 2021); (2) High integration of models, systems and data (Koulamas et al. and Xiang F et al. 2018 ); (3) The simulation's degree of realism is low (Teng et al. 2021). In addition, the lack of a reference framework for DTs' fundamental building elements also makes them hard to practice (Josifovska et al. 2019). Because these difficulties limit the success of various industries experiencing digital transformations, DT urgently requires breakthrough solutions.

This study summarizes the demand features of DTs and describes their current state of research. The composition framework, development model, and core technology of DTs are proposed based on the features of DTs. To ensure the framework's viability, take a project in Shandong as an example. The project needs the creation of a complicated logistics management 3D dispatching and monitoring system. DT and VR are two primary technologies utilized in the virtual world to complete equipment debugging and system operation ( $\mathrm{Du} \mathrm{J}$ et al. 2020). The case describes the construction process and the benefits to the company, demonstrating that DT technology plays a vital part in the company's flexible production management.

There are six parts to the article. The next part discusses the current state of research on the topic of this article. The third section covers the framework's design, including development concepts, core technologies, and a software overview. The fourth section offers a case study that demonstrates DTs how improve production management. The fifth section examines the case study's results and lessons gained. Finally, a summary of this study is presented, as well as future research directions.

\section{Background}

In recent years, the use of VR(Virtual Reality) and DTs has covered a wide range of engineering fields, including design, production, manufacturing, and maintenance (Burghardt et al. 2020; Errandonea et al. 2020). Consider the following dimensions of DTs in the analysis of science and application: (1) breadth of integration, (2) dual-system connection mode, (3) information update frequency, (4) CPS intelligence, (5) simulation capability, (6) digital Model richness, (7) human-computer interaction (8) product life cycle (Stark R et al. 2019). In general, maximizing the usage of DT technology may increase the enterprise's production and efficiency while reducing the loss caused by downtime or equipment troubleshooting. The advantages of DTs will encourage businesses to the digital transformation.

\subsection{Flexible Production Management}

DTs are an indispensable technology for realizing intelligent factories (Eckhart et al. 2018). But the most frequent function of all DT practices is maintenance. The results of predicting the number of failures obtained from DT show that DTs can achieve a high degree of flexible management (Shubenkova et al. 2018). In addition, the maintenance is also based on transforming the real world into VR by presenting high-precision 3D models for remote maintenance guidance and equipment service life prediction. To overcome the problem of long simulation time in the past, Abdelmegid M A et al. (2021) proposed a 
framework that combines simulation modeling practice with the Last Planner VR system to bridge this gap.

A petrochemical plant implements intelligent production control based on DT technology (Min Q et al., 2019), and a product assembly workshop implements flexible production and management based on DTs (Cunbo et al. 2018). These two studies both reflect the application of DTs in flexible production and management. But most academic research focuses on optimizing models rather than the actual implementation of DTs (Tao F et al. 2019). So most of the article is still at the stage of theoretical.

\subsection{Digital Twin}

The DT expands the previous simulation model and can carry out the simulation operation of the authentic system (Bilberg et al. 2019). However, this has created several difficulties, including how to synchronize virtual and actual production systems (Batty et al. 2018)? Also, how can real-time data and the command be sent and received between the two platforms? To synchronize with the authentic production system, Talkhestani B A et al. (2018) recommended that the data of the virtual simulation model be updated using the anchor point approach. To solve the double-layer online intelligence of manufacturing resources, one can refer to the panel product intelligent manufacturing workshop driven by DTs in parallel (Leng et al. 2019). The study indicated above is based on practice to produce advancements in DTs from a single point of view, such as data synchronization and model optimization. However, enterprises will have difficulty implementing DTs without a systematic architecture.

The research on the DT architecture begins with the definition and characteristics of the concept (Autiosalo et al. 2019). The second is DT case studies at various stages of the product life cycle. For example, the research on the implementation framework of DT in the welding production line (Zheng et al. 2019). The importance of DT research for businesses is to increase the added value of products at every step of their life cycle (Erkoyuncu et al. 2018). This study builds the framework of the DT based on the real demands of the enterprise and the basic concept of the DT, drawing on the benefits of the previous research. The majority of the studies cited above research the DT from a single perspective. In this regard, this essay will explore the systematic structure of DTs while combining the features of DTs in the product manufacturing and service phases.

\subsection{D Visualization and Virtual Reality}

The development and testing of physical devices have become the key barrier for successful production as product complexity has increased and product life cycles have shrunk. Using "virtual prototype" technology in the design process to eliminate hardware testing and iteratively enhance physical prototypes, on the other hand, will save businesses a significant amount of money and time (Gromova 2019). High-precision simulation based on the construction of sophisticated 3D physical models, on the other hand, is highly costly in terms of computation and time, severely limiting its use (Wang B et al. 2020). Before production equipment, DT assists in visualizing the design in 3D and doing virtual testing and simulations (Yaqoob et al. 2020). Improve the product design environment and decrease the development expenses through visual monitoring of the manufacturing process and virtual manufacture 
of the DT (Shahriar et al. 2018). Use 3D point clouds to reconstruct and visualize the conditions of the built environment, making VR closer to reality (Stojanovic et al. 2018). According to studies, combining DTs with 3D visualization can increase the functional adaptability of each other, opening up additional opportunities for further DT investigation.

VR is applied in a variety of sectors to provide tangible and significant advantages. Such as urban planning, real estate marketing, architectural design, and others. VR will play a key role In product design and development, as well as quality production management. Because it can reduce the design cycle, boost project completion quality, and lower investment and development expenses. This study establishes a DT framework by combining VR and 3D visualization technologies for DTs to better boost company production management.

\section{Build A Framework}

The framework refers to a specific DT hierarchical structure, information required for modeling, and modeling methods ( $L u$ Y et al. 2018). The framework facilitates the design, optimization, and control of human-machine cooperation throughout the product development process (Wagner et al. 2019; Malik et al. 2018), allowing users to create and execute DTs (Eckhart et al. 2018). The system structure, information synchronization, models, and how to merge these parts into a framework must consider while constructing a DT (Wu B et al. 2020). First, reduced-order modeling is trustworthy enough for predicting DTs while yet allowing for rapid evaluation (Kapteyn et al. 2020). Second, the PLC (Programmable logic controller) system collects data from the assembly system, then synchronizes with the virtual model in the DT through the open platform communication server (Židek et al. 2020). Finally, this section will introduce the DT's development model, core technologies, and framework. The actual cases in this article will prove the feasibility of the framework.

\subsection{Design features}

This article synthesizes many perspectives on the characteristics of DTs and to summarizes its key features, such as the simultaneous operation of virtual and actual production systems, rapid information gathering, and system integration (Talkhestani et al. 2019; Shao G et al. 2020). They are two categories as manufacturing and service to explain these features.

\subsubsection{Manufacturing stage}

The utilization of digital twins in the product production stage can reduce product introduction time and boost product delivery speed. It may increase product quality, optimize processes, and lower product manufacturing costs in production management. Create a virtual manufacturing line using digital twin technologies to track all material production and circulation processes. The following three points are the vital roles of the virtual system in the product production stage. 
(1) Product design and virtual commissioning: Virtual commissioning of physical equipment and software systems during equipment manufacture can decrease the debug's error and accelerate the project timeline. Product design in virtual systems can help to accelerate the introduction of new goods while also lowering the cost of product design.

(2) Digital production line: Using DT for information like materials and equipment throughout the manufacturing process. Simultaneously, it collects numerous data from the manufacturing process to offer a foundation for future analysis and optimization.

(3) Process capability evaluation and vital indicator monitoring: Collect real-time operational data from different production equipment on the production line of the whole manufacturing process to provide a visual monitor. To ensure the normal functioning of the manufacturing process, set KPI monitoring policies and vital device parameters. Furthermore, analyzing the information gathered may optimize operations to improve product quality and productivity.

\subsubsection{Service stage}

Many enterprises now utilize large sensors to gather data and apply data analysis to avert production failures, enhancing product quality, thanks to the maturation of loT technology and the drop in sensor costs. The digital twin at the service stage helps the enterprise's flexibility management in the following two areas.

(1) Remote monitoring and equipment maintenance: For instance, visible remote control of virtual systems may help businesses save labor expenses and personnel aggregation. Second, you may develop a monitoring system for device health indicators using data acquired by the authentic scene. Artificial intelligence and machine learning allow for the prediction of equipment usage, assist the management of maintenance and replacement parts, and reduce losses caused by unscheduled outages.

(2) Enhance production efficiency: Equipment makers may construct experience models for numerous application situations and manufacturing processes to improve product quality and production efficiency by accumulating a large amount of production data.

\subsection{System design}

This section will introduce the basic steps of building a DT, including development models, key technologies, and system frameworks.

\subsubsection{Development model}

To compare the development model of DTs with classical simulation in this part. As seen in Figure 1, an engineering project frequently necessitates engineering design first, followed by a wait for manufacturing equipment. After installing the physical equipment, debugging is required to confirm the equipment's regular operation. In general, waiting for equipment manufacture integration and installation might take up to two months. Previously, 3D modeling lacked a solid model, but DT's 3D modeling now has one, 
allowing for a proportion of 1:1 restoration of the actual world. Given this, using DT can debug the equipment in advance in the virtual world, hence shortening the project's building duration. The most crucial point is that the previous simulations include a lot of repeated work, which will result in a lot of unnecessary expenditures. However, the DT development model may run many programs at the same time, saving time. Simultaneously, virtual debugging equipment can lower the cost of debugging. As a result, DT's product development model may save time and money than the typical simulated linear development strategy.

\subsubsection{How to build a DT?}

Figure 2 shows that the framework of the DT. The early stage, middle stage, and late-stage are the three primary stages of phased work. The early stages mostly need study and data gathering. Combine client demands and data to create a systematic design strategy that will serve as the foundation for future modeling and software development. The data gathering process includes the integration and analysis of product production data and equipment operating data. The main goal of the mid-term task is to create models in the virtual world using manual data and to present the realistic environment in a 1:1 ratio for 3D modeling. The model in the virtual world requires the visual effect to be close to reality, and the model's material must be consistent with actuality in terms of data. It lays the foundation for enterprises in the management of equipment use. Finally, based on the previous, the system simulation operation is carried out through the virtual scene made by the model. Here, by writing abundant data codes to achieve dynamic constraints to ensure the operation and dynamical display of the entire system. Including physical equipment debugging and software system debugging. After debugging the whole system, it can be installed and used directly in real life.

In general, the construction of a DT is mainly composed of four steps: collecting data, modeling, debugging, and installation and joint debugging. The real system is synced with the virtual system once it deploys by collecting data from different sensors and transferring data from the server. Data is transferred in real-time between them. The complete system may be executed in a virtual scenario using PLC interface technology, allowing for remote synchronization. Remote synchronization will serve the enterprise's production management and equipment auxiliary maintenance. The phases and functions listed above cover the complete enterprise's production and operating cycle. It may oversee and service the whole business process, assisting the company in increasing operational efficiency and improving its automated management capabilities.

\section{Case Study}

This article utilizes a project in Shandong as an example to demonstrate the framework's applicability. The purpose is to construct a set of ILM3DSMS(Intelligent logistics management 3D scheduling monitoring systems) for a plant in Shandong using DTs. Figure 3 shows the project's execution processes, including eight routines, which are demand analysis, system design, 3D modeling and software design, system simulation, virtual debugging, system installation, and project acceptance. The existing scheduling interface can display all production processes and no more blind spots. Users can 
intuitively monitor all areas with this monitoring system, which entirely replaces the old monitoring system. This project has improved the flexibility of business production management after applying this monitoring system. The project includes a production area, storage area, and sorting area, with a 396-day building timeframe. After testing, the firm has successfully accepted it.

\subsection{Survey of Demand}

Investigate and evaluate the enterprise's management needs to develop project goals. The purpose is to gather production equipment operating data over the Industrial Internet and employ DT technology to accomplish equipment digitalization and 3D visualization based on the demands of businesses. The result needs a monitoring and dispatching system to achieve effective on-site and remote equipment operation and maintenance management solutions while improving manufacturing quality.

\subsection{Intelligent logistics management software design for a 3D dispatch control system}

ILM3DSM is the creation of a logistics management system using DT technology. Software design and 3D modeling are going together simultaneously, and they are then debugged jointly in the virtual system. This section will introduce the software components and functionalities used in this system.

The made-up of This software system is preliminarily expecting with WMS (Warehouse Management System), VRWCS (Virtual Reality Warehouse Control System), INF (Device INFormation File), VRMTS (Virtual Reality Model Test System) based on the demands of businesses. Fig. 4 shows the interrelationship between software. Although the software is connected, there are still levels, and the WMS system belongs to the top-level scheduling system. VRWCS is a WCS that simulates reality, and it directly controls the various independent devices at the bottom. The INF docks with information systems of the enterprise to ensure the synchronization and docking of information. The main functions of each software are as follows.

The WMS is in charge of the whole process scheduling and management, as well as information tracking. The main functions are as follows:

(1) Material management: fundamental master data is synchronized with MES information and supports 4-5 attribute columns of the same material;

(2) Graphical management: no less than 10 million pixel camera equipment, the items are taken and kept before entering and exiting the warehouse, which is convenient for inspection and proofreading;

(3) Inbound and outbound management: Inbound list management, material inbound location prearrangement, label printing, automatic interaction with MES, automatic location matching, first-in-first-out, manual intervention; 
(4) Storage management: storage and exit principles such as roadway balance, proximity principle, firstin-first-out, efficiency priority, manual intervention, automatic pre-arrangement, etc.;

(5) Comprehensive information query and report management: comprehensive information automatic query, inventory status, change analysis, inbound and outbound statistics, cargo location and equipment utilization, etc.;

(6) Security management: user role and authority management;

(7) Inventory management: Item location adjustment, inventory management, inventory safety management (inventory overtime alarm, alarm outside the preset safety range).

VRWCS is mainly responsible for simulating realistic electrical control and testing the scheduling problems of the entire system. Its main functions and features are as follows:

(1) Comprehensive dispatching and equipment dispatching: accepting warehouse instructions and automatically decomposing them to the executing equipment; real-time detection of equipment operating status and location, and simulation monitoring of the material status in the system;

(2) Path management: provide optimal path management for logistics; temporarily plan and add new paths;

(3) Task management: Can forcibly cancel and suspend tasks;

(4) Fault handling and operation log: automatically report equipment faults and self-diagnose; automatically provide fault handling interface and log information.

VRWCS has the following characteristics:

(1) Make 3D scenes in a 1:1 ratio;

(2) Solve that users can directly and intuitively control the overall logistics operation status and inventory status;

(3) Intuitive display of cargo location information and material information, and one person can monitor the entire system.

INF is mainly responsible for system docking and data processing. It adopts the current advanced and standard interface method to connect enterprise ERP, MES, and other related systems.

The main functions of VRMTS are scheduling control testing and PLC data visualization. The purpose of the scheduling control test is potential problems can be identified and resolved in advance. The PLC data visualization is primarily responsible for the communication status, ensuring communication between the actual WCS and the virtual system's WCS. 


\subsection{System Development}

System development includes creating a three-dimensional model in the virtual environment and debugging equipment and software systems. Program the established 3D model and debug the virtual physical equipment. Simultaneously, debug the software system, eliminate any issues, and optimize it until it is ready to be put in the firm.

\subsubsection{D modeling}

In the past, simulation modeling required engineering design first, followed by modeling. 3D modeling may be done directly according to the scenario with the new 3D modeling software, saving a lot of time than before modeling. "Zhongwushi" is the modeling and simulation software utilized in this study (The design software is shown in Fig. 5). The difference between the DT's 3D modeling and earlier simulation modeling is that the previous simulation modeling lacks a model, making it impossible to troubleshoot. Fig. 6 depicts a device model in the DT's three-dimensional modeling. The logistics equipment in the virtual system and the actual equipment have a 1:1 correspondence. The 3D scene modeling should base on the authentic scenario, and the size, look, and other aspects of the logistical equipment should correspond to the actual circumstances.

\subsubsection{Debugging}

After finishing the 3D modeling, can create code for the complete model so it can run. Virtual Debugging entails both the installation of hardware and the scheduling management of the software system. The software system scheduling control is to load the entire intended software system into the hardware equipment in the virtual scene and test the software system to determine if there will be any difficulties with the system. Testing in a virtual system helps detect and address problems in advance, reducing debugging time. After debugging is complete, the software can implement in reality.

Furthermore, whether it is design, production, or service, accurate measurement of numerous qualities, parameters, and operational state of physical entities is required to accomplish exact analysis and optimization. However, to achieve good measurement results, these needs rely on expensive physical measuring gear such as sensors, acquisition systems, detecting systems, and so on. However, this will limit the extent of measurement coverage and result in the loss of monitoring for many indicators that cannot be collected directly. The DT technology can employ the loT and big data technologies to infer some signs that machine learning cannot straightly monitor, saving organizations money on administration.

In the case study of this article, a total of 8 different types of bugs appeared during debugging (Table 1 shows these bugs). Compared to the prior on-site debugging volume, discovering using digital twin technology for virtual debugging has reduced debugging faults by $70 \%$. 
Table 1

Show the issues that arose throughout the debugging process

\begin{tabular}{|ll|}
\hline $\begin{array}{l}\text { Serial } \\
\text { number }\end{array}$ & Problems in case debugging \\
\hline 1 & The program is not working \\
\hline 2 & The software system's assignment is erroneous, resulting in a disordered program \\
\hline 4 & The platform equipment's height is improper, and the stacker cannot take up the products \\
\hline 5 & $\begin{array}{l}\text { The motor's rotational direction is incorrect and cannot transport the material } \\
\text { transmission between the two stations failed }\end{array}$ \\
\hline 6 & Poor power contact of a motor causes the conveyor to be unstable \\
\hline 7 & The frequency of wireless transmission is wrong, and the signal transmission fails \\
\hline 8 & A disturbed scheduler leads to inefficient equipment \\
\hline 4
\end{tabular}

\subsection{Installation of the system}

After the installation is complete, the information should sync between virtual with real-world, and the different information interfaces and systems may be synchronized and docked. The 3D scheduling monitoring technology enables managers to watch the whole production and operating process immediately.

The following are the results of the intelligent logistics management 3D dispatching monitoring system:

First, employ holographic effects to display materials or equipment based on user requirements and give a virtual digital signage function. Users may view the operational status of different equipment (such as stackers, conveyors, robots, shuttles, and so forth) via the monitoring screen (as shown in Figure 7). In terms of visual sense, the system supports a maximum of 20,000 data collecting points and a maximum of 75 frames per second throughout all operations.

Second, there will be a visual depiction of the cargo location as well as material details supplied. The monitoring interface displays material brand, amount, stack type, and other information in 3D. On the same interface, the operator can visually inspect and check the material information, which is helpful for inventory (Figure 8 shows the effect).

Furthermore, it offers organizations a VR scene system with a feeling of immersion identical to the actual logistics scenario. After donning the VR helmet, the manager may freely traverse the virtual scene and learn about the project's actual logistical operation procedure. The VR helmet renders at a rate of at least 75 frames per second. The primary role of VR helmets is to teach new employees, assist new employees in understanding the production condition, provide off-site advice during equipment maintenance, and 
assist enterprises in quickly resolving equipment failure problems, resuming production, and reducing losses.

\section{Findings And Lessons Learned}

After preparation, design, development, debugging, and installation, the project is finished and ready for acceptance. However, during the project's implementation, uncovered some issues. This section will discuss the effectiveness of DTs in boosting corporate flexibility management. Simultaneously, comparing the findings of this study to current research on DTs in manufacturing and application. Finally, discuss the issues of DTs in flexible production management.

This project primarily increases the flexibility of corporate production management in the following areas. First of all, virtual debugging based on DT technology has reduced debugging faults by $70 \%$. Second, the system addresses the production enterprise's low equipment maintenance efficiency and high maintenance expenses. When production line equipment fails, it may minimize failure recovery time, enhance production efficiency, reduce operating costs, reduce the needs on the ability of on-site maintenance people, and efficiently handle equipment maintenance pain points. Finally, using the Industrial Internet's remote maintenance guidance technology and comparing the number and cost of the firm's prior staff, it has been discovered that the system can save the company $40 \%$ of labor costs. In addition, remote equipment maintenance instruction can save equipment makers around $50 \%$ in trip costs. It can swiftly adapt to the enterprise's demands and improve the enterprise's production management flexibility. Most importantly, the system may effectively reduce staff travel and gathering during the epidemic time while assuring production work development.

Furthermore, when the equipment is running, the system will gather status information, allowing operation workers to remotely and intuitively grasp the working state of the equipment. The fault system may automatically send problem information to the mobile phones of operation and maintenance workers to ensure regular production. According to the example's scene error data, the time error of the large scene between the real and virtual system is within 1 second, while the time error of the little scene is within 200 milliseconds, achieving full synchronization.

Table 2 compares DTs in production management to others. As can be seen, the function of DT technology varies depending on the situation and product cycle. Compared with $\mathrm{Ma} \mathrm{J}$ et al. (2020), the main difference lies in the product life cycle. This study and Cimino et al. (2019) are based on practice to tackle difficulties when using DTs. But the focus of this study is on the synchronized operation and information transfer between the two systems to improve business management. Cunbo $Z$ and Leng $\mathrm{J}$ are primarily a bias towards studies done on specific factories for DTs. The framework provided in this article is more comprehensive and does not constrain the industry's goods. The study mentioned above has some application value for businesses, but the company's situation decides the specific implementation. 
Table 2

A comparison of digital twins applied research

\begin{tabular}{|c|c|c|c|}
\hline Author & Contribution & Effect & Contrast \\
\hline $\begin{array}{l}\text { Ma J, } \\
\text { Chen H, } \\
\text { Zhang Y, } \\
\text { et al. }\end{array}$ & $\begin{array}{l}\text { To address how to create a } \\
\text { digital twin-driven } \\
\text { production management } \\
\text { system for product life cycle } \\
\text { management. }\end{array}$ & $\begin{array}{l}\text { The faulty product rate and } \\
\text { work-in-process inventory } \\
\text { were decreased by } 34 \% \text { and } \\
89 \% \text {, respectively, while the } \\
\text { product's first-time inspection } \\
\text { pass rate climbed by } 14.2 \\
\text { percent. }\end{array}$ & $\begin{array}{l}\text { The case's debugging } \\
\text { bugs were decreased } \\
\text { by } 70 \% \text {, and the } \\
\text { operation and } \\
\text { maintenance } \\
\text { employees were cut by } \\
40 \% \text {. }\end{array}$ \\
\hline $\begin{array}{l}\text { Cimino C, } \\
\text { Negri E, } \\
\text { Fumagalli } \\
\text { L }\end{array}$ & $\begin{array}{l}\text { At the Politecnico di Milano's } \\
\text { School of Management to } \\
\text { implement DT in a } \\
\text { laboratory equipped with } \\
\text { MES. }\end{array}$ & $\begin{array}{l}\text { Create applications that } \\
\text { provide the groundwork for } \\
\text { addressing the questions in } \\
\text { the literature. }\end{array}$ & $\begin{array}{l}\text { Create a digital twin } \\
\text { architecture to enable } \\
\text { synchronized } \\
\text { operation of virtual } \\
\text { and physical systems. }\end{array}$ \\
\hline $\begin{array}{l}\text { Cunbo Z, } \\
\text { Liu J, } \\
\text { Xiong H }\end{array}$ & $\begin{array}{l}\text { A framework of intelligent } \\
\text { production management } \\
\text { and control techniques for } \\
\text { sophisticated product } \\
\text { assembly workshops is } \\
\text { proposed based on digital } \\
\text { twins. }\end{array}$ & More specific. & $\begin{array}{l}\text { Propose a framework } \\
\text { for the composition of } \\
\text { digital twins (extensive, } \\
\text { not restrictive to the } \\
\text { industry). }\end{array}$ \\
\hline $\begin{array}{l}\text { Leng J, } \\
\text { Zhang H, } \\
\text { Yan D, et } \\
\text { al. }\end{array}$ & $\begin{array}{l}\text { The authors apply DT at a } \\
\text { laboratory equipped with } \\
\text { MES at the Politecnico di } \\
\text { Milano's Management } \\
\text { School. }\end{array}$ & & \\
\hline
\end{tabular}

Finally, finding some issues with DTs throughout the project's execution. According to research, while machine learning opens up numerous possibilities for DTs, some circumstances will be limiting their applicability. The low degree of automation and informatization of businesses, for example, will make it impossible for DTs to acquire fundamental data. The services available in other phases will not be constrained if the DT does not need to execute simultaneously with the authentic system. For example, there are rarely needing with external systems during the product design process.

\section{Conclusion}

Through design tools, simulation tools, the loT, VR, and other digital methods, DTs translate numerous features of physical equipment into virtual space to produce disassembly, capability, transferability, modification, and deletion. It can make some procedures that would otherwise be impossible to accomplish because of physical constraints, speeding up the operator's knowledge of them. This article suggests a digital twin framework based on virtual reality and 3D visualization technology in this regard. And, using a case study, introduce its construction approach and demonstrate its viability. The results reveal that the framework allows the dual systems to synchronous operation. The case is sufficient to prove that the DT technology is of great significance for improving the flexible production management of the enterprise. However, the case is mainly due to the needs of the enterprise, mainly in the production 
scheduling monitoring and later equipment maintenance, data analysis, and technical support. There are no corresponding cases in the product design stage, but companies can still apply DT technology by the framework.

The application scope of DTs is gradually expanding, and the question of how to leverage this technology to assist businesses is currently a hot topic of research. Because of the current situation of China's research on the application of DT technology, it has gradually begun to explore the digital supply chain. The research on the digital supply chain will enhance the integrity and systemic of the enterprise, and future research will also rely on this field.

\section{Declarations}

- Funding

The authors did not receive support from any organization for the submitted work.

- Conflict of interest/Competing interests (check journal-specific guidelines for which heading to use)

The authors have no relevant financial or non-financial interests to disclose.

- Availability of data and materials

The data may be available upon request for some of the participatingcenters but not for all due to relevant data protection laws. The data in this paper came from the operation data of the enterprise, which declined to provide the original data.

- Code availability

The code involves the core business data of the enterprise, and the enterprise refuses to provide the original code.

- Ethics approval

Informed consent

- Consent to participate

All authors agree to participate.

- Consent for publication

All authors agree to publish.

- Authors' contributions 
All authors contributed to the study conception and design. Material preparation, data collection and analysis were performed by [Wenxue Ran], [Yimin Hu] and [Zhi Yang]. The first draft of the manuscript was written by [Yimin $\mathrm{Hu}$ ] and all authors commented on previous versions of the manuscript. All authors read and approved the final manuscript.

\section{References}

1. Barricelli BR, Casiraghi E, Fogli D (2019) A survey on digital twin: definitions, characteristics, applications, and design implications[J]. IEEE access 7:167653-167671

2. Souza V, Cruz R, Silva W et al (2019) A digital twin architecture based on the industrial internet of things technologies[C]//2019 IEEE International Conference on Consumer Electronics (ICCE). IEEE, : 12

3. Kaur MJ, Mishra VP, Maheshwari P (2020) The convergence of digital twin, loT, and machine learning: transforming data into action[J].Digital twin technologies and smart cities, :3-17

4. Bolton RN, McColl-Kennedy JR, Cheung L et al (2018) Customer experience challenges: bringing together digital, physical and social realms[J].Journal of Service Management,

5. Burgos D, Ivanov D (2021) Food retail supply chain resilience and the COVID-19 pandemic: A digital twin-based impact analysis and improvement directions[J]. Transp Res E 152:102412

6. Madni AM, Madni CC, Lucero SD (2019) Leveraging digital twin technology. in model-based systems engineering[J] Systems 7(1):7

7. Lu Y, Liu C, Kevin I et al (2020) Digital Twin-driven smart manufacturing: Connotation, reference model, applications and research issues[J]. Robotics and Computer-Integrated Manufacturing, 61: 101837

8. Liu Q, Leng J, Yan D et al (2021) Digital twin-based designing of the configuration, motion, control, and optimization model of a flow-type smart manufacturing system[J]. J Manuf Syst 58:52-64

9. Stojanovic N, Milenovic D (2018) Data-driven digital twin approach for process optimization: an industry use case[C]//2018 IEEE International Conference on Big Data (Big Data). IEEE, : 4202-4211

10. Ayani M, Ganebäck M, Ng AHC (2018) Digital Twin: Applying emulation for machine reconditioning[J]. Procedia Cirp 72:243-248

11. Haag S, Anderl R (2018) Digital twin-Proof of concept[J]. Manufacturing Letters 15:64-66

12. Macchi M, Roda I, Negri E et al (2018) Exploring the role of digital twin for asset lifecycle management[J]. IFAC-PapersOnLine 51(11):790-795

13. Anderl R, Haag S, Schützer K et al (2018) Digital twin technology-An approach for Industrie 4.0 vertical and horizontal lifecycle integration[J]. it-Information Technology 60(3):125-132

14. Liu S, Bao J, Lu Y et al (2021) Digital twin modeling method based on biomimicry for machining aerospace components[J]. J Manuf Syst 58:180-195

15. Bruynseels K, Santoni de Sio F, van den Hoven J (2018) Digital twins in health care: ethical implications of an emerging engineering paradigm[J]. Front Genet 9:31 
16. Barricelli BR, Casiraghi E, Gliozzo J et al (2020) Human digital twin for fitness management[J]. leee Access 8:26637-26664

17. Toivonen $\mathrm{V}$, Lanz $\mathrm{M}$, Nylund $\mathrm{H}$ et al (2018) The FMS Training Center-a versatile learning environment for engineering education[J]. Procedia Manufacturing 23:135-140

18. Fuller A, Fan Z, Day C et al (2020) Digital twin: Enabling technologies, challenges and open research[J]. IEEE access 8:108952-108971

19. Rasheed A, San O, Kvamsdal T (2019) Digital twin: Values, challenges and enablers[J]. arXiv preprint arXiv:1910.01719,

20. Shao G, Jain S, Laroque C et al (2019) Digital twin for smart manufacturing: The simulation aspect[C]//2019 Winter Simulation Conference (WSC). IEEE, : 2085-2098

21. Tao F, Qi Q, Wang L et al (2019) Digital twins and cyber-physical systems toward smart manufacturing and industry 4.0: Correlation and comparison[J]. Engineering 5(4):653-661

22. Saracco R (2019) Digital twins: Bridging physical space and cyberspace[J]. Computer 52(12):58-64

23. Wright L, Davidson S (2020) How to tell the difference between a model and a digital twin[J]. Advanced Modeling and Simulation in Engineering Sciences 7(1):1-13

24. Kritzinger W, Karner M, Traar G et al (2018) Digital Twin in manufacturing: A categorical literature review and classification[J]. IFAC-PapersOnLine 51(11):1016-1022

25. Bao J, Guo D, Li J et al (2019) The modelling and operations for the digital twin in the context of manufacturing[J]. Enterprise Information Systems 13(4):534-556

26. Putz B, Dietz M, Empl P et al (2021) Ethertwin: Blockchain-based secure digital twin information management[J]. Inf Process Manag 58(1):102425

27. Koulamas C, Kalogeras A (2018) Cyber-physical systems and digital twins in the industrial internet of things [cyber-physical systems][J]. Computer 51(11):95-98

28. Xiang F, Zhi Z, Jiang GZ (2018) Digital Twins technolgy and its data fusion in iron and steel product life cycle[C]//2018 IEEE 15th international conference on networking, sensing and control (ICNSC). IEEE, : 1-5

29. Teng SY, Touš M, Leong WD et al (2021) Recent advances on industrial data-driven energy savings: Digital twins and infrastructures[J]. Renew Sustain Energy Rev 135:110208

30. Josifovska K, Yigitbas E, Engels G (2019) Reference framework for digital twins within cyber-physical systems[C]//2019 IEEE/ACM 5th International Workshop on Software Engineering for Smart CyberPhysical Systems (SEsCPS). IEEE, : 25-31

31. Du J, Zhu Q, Shi Y et al (2020) Cognition digital twins for personalized information systems of smart cities: Proof of concept[J]. J Manag Eng 36(2):04019052

32. Burghardt A, Szybicki D, Gierlak P et al (2020) Programming of industrial robots using virtual reality and digital twins[J]. Applied Sciences 10(2):486

33. Errandonea I, Beltrán S, Arrizabalaga S (2020) Digital Twin for maintenance: A literature review[J]. Comput Ind 123:103316 
34. Stark R, Fresemann C, Lindow K (2019) Development and operation of Digital Twins for technical systems and services[J]. CIRP Ann 68(1):129-132

35. Eckhart M, Ekelhart A (2018) A specification-based state replication approach for digital twins[C]//Proceedings of the 2018 Workshop on Cyber-Physical Systems Security and Privacy. : 3647

36. Shubenkova K, Valiev A, Shepelev V et al (2018) Possibility of digital twins technology for improving efficiency of the branded service system[C]//2018 global smart industry conference (GloSIC). IEEE, : 1-7

37. Abdelmegid MA, González VA, O'Sullivan M et al (2021) Exploring the links between simulation modelling and construction production planning and control: a case study on the last planner system[J]. Production Planning \& Control, pp 1-18

38. Min Q, Lu Y, Liu Z et al (2019) Machine learning based digital twin framework for production optimization in petrochemical industry[J]. Int J Inf Manag 49:502-519

39. Cunbo Z, Liu J, Xiong H (2018) Digital twin-based smart production management and control framework for the complex product assembly shop-floor[J]. The international journal of advanced manufacturing technology 96(1-4):1149-1163

40. Tao F, Qi Q (2019) Make more digital twins[J]. Nature 573(7775):490-491

41. Bilberg A, Malik AA (2019) Digital twin driven human-robot collaborative assembly[J]. CIRP Ann 68(1):499-502

42. Batty M (2018) Digital twins[J]. Environment and Planning. Urban Analytics and City Science 45(5):817-820

43. Talkhestani BA, Jazdi N, Schlögl W et al (2018) A concept in synchronization of virtual production system with real factory based on anchor-point method[J]. Procedia Cirp 67:13-17

44. Leng J, Zhang H, Yan D et al (2019) Digital twin-driven manufacturing cyber-physical system for parallel controlling of smart workshop[J]. J Ambient Intell Humaniz Comput 10(3):1155-1166

45. Autiosalo J, Vepsäläinen J, Viitala R et al (2019) A feature-based framework for structuring industrial digital twins[J]. IEEE Access 8:1193-1208

46. Zheng Y, Yang S, Cheng $\mathrm{H}$ (2019) An application framework of digital twin and its case study[J]. J Ambient Intell Humaniz Comput 10(3):1141-1153

47. Erkoyuncu JA, Butala P, Roy R (2018) Digital twins: Understanding the added value of integrated models for through-life engineering services[J]. Procedia Manufacturing 16:139-146

48. Gromova EA (2019) Digital economy development with an emphasis on automotive industry in Russia[J].Revista Espacios, 40(06)

49. Wang B, Zhang G, Wang $\mathrm{H}$ et al (2020) Multi-physics-resolved digital twin of proton exchange membrane fuel cells with a data-driven surrogate model[J]. Energy and Al 1:100004

50. Yaqoob I, Salah K, Uddin M et al (2020) Blockchain for digital twins: Recent advances and future research challenges[J]. IEEE Network 34(5):290-298 
51. Shahriar MR, Al Sunny SMN, Liu X et al (2018) MTComm based virtualization and integration of physical machine operations with digital-twins in cyber-physical manufacturing cloud[C]//2018 5th IEEE International Conference on Cyber Security and Cloud Computing (CSCloud)/2018 4th IEEE International Conference on Edge Computing and Scalable Cloud (EdgeCom). IEEE, : 46-51

52. Stojanovic V, Trapp M, Richter R et al (2018) Towards the generation of digital twins for facility management based on 3D point clouds[J]. Management 270:279

53. Lu Y, Xu X (2018) Resource virtualization: a core technology for developing cyber-physical production systems[J]. J Manuf Syst 47:128-140

54. Wagner R, Schleich B, Haefner B et al (2019) Challenges and potentials of digital twins and Industry 4.0 in product design and production for high performance products[J]. Procedia CIRP 84:88-93

55. Malik AA, Bilberg A (2018) Digital twins of human robot collaboration in a production setting[J]. Procedia manufacturing 17:278-285

56. Eckhart M, Ekelhart A (2018) Towards security-aware virtual environments for digital twins[C]//Proceedings of the 4th ACM workshop on cyber-physical system security. : 61-72

57. Wu B, Widanage WD, Yang S et al (2020) Battery digital twins: Perspectives on the fusion of models, data and artificial intelligence for smart battery management systems[J]. Energy and Al 1:100016

58. Kapteyn MG, Knezevic DJ, Huynh DBP et al (2020) Data-driven physics-based digital twins via a library of component-based reduced-order models[J]. International Journal for Numerical Methods in Engineering

59. Židek K, Pitel' J, Adámek M et al (2020) Digital twin of experimental smart manufacturing assembly system for industry 4.0 concept[J]. Sustainability 12(9):3658

60. Talkhestani BA, Jung T, Lindemann B et al (2019) An architecture of an intelligent digital twin in a cyber-physical production system[J]. at-Automatisierungstechnik 67(9):762-782

61. Shao G, Helu M (2020) Framework for a digital twin in manufacturing: Scope and requirements[J]. Manufacturing letters 24:105-107

62. Ma J, Chen $\mathrm{H}$, Zhang $\mathrm{Y}$ et al (2020) A digital twin-driven production management system for production workshop[J]. The International Journal of Advanced Manufacturing Technology 110(5):1385-1397

63. Cimino C, Negri E, Fumagalli L (2019) Review of digital twin applications in manufacturing[J]. Comput Ind 113:103130

\section{Figures}




\section{Comparison of product development model based on digital twin technology and traditional product development model}

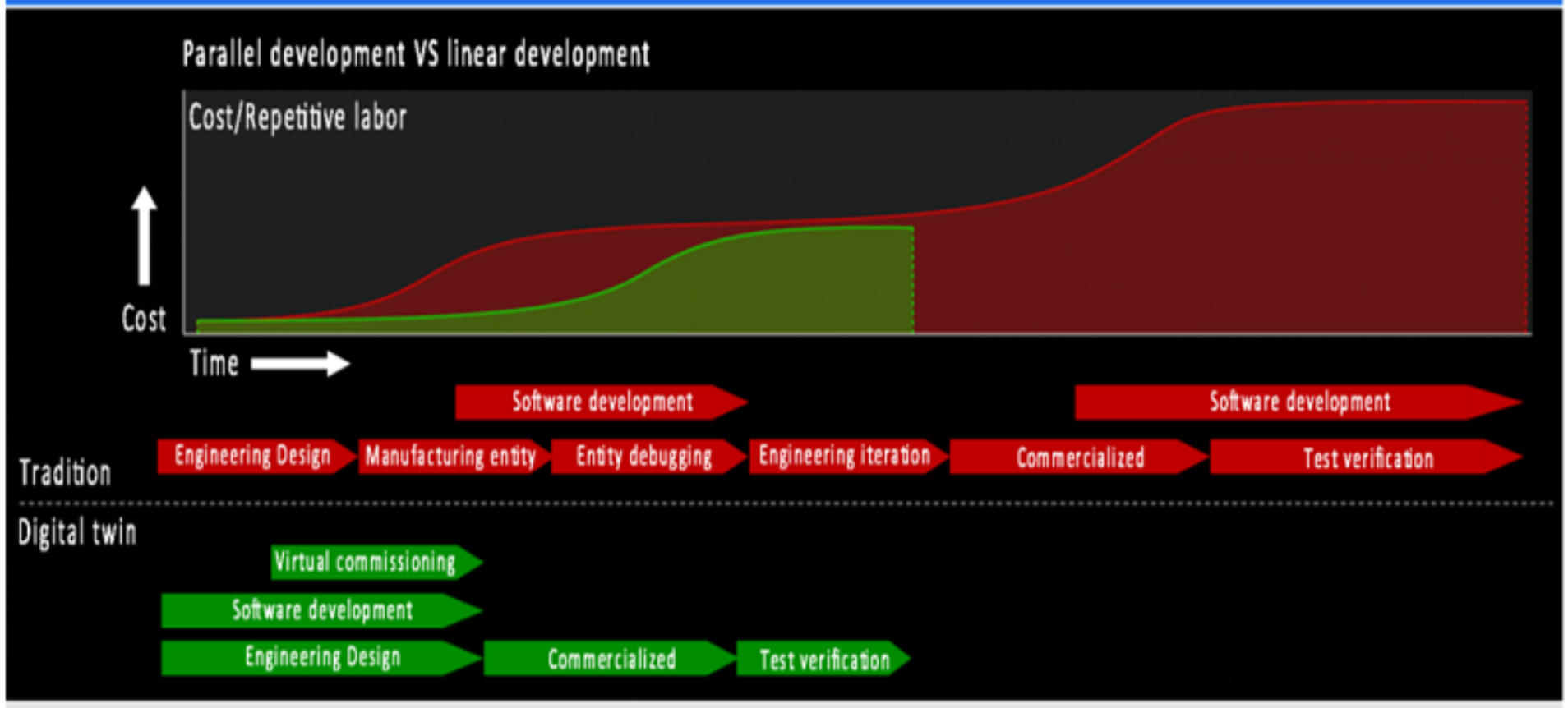

\section{Figure 1}

To compare the development models

The digital twin's architecture

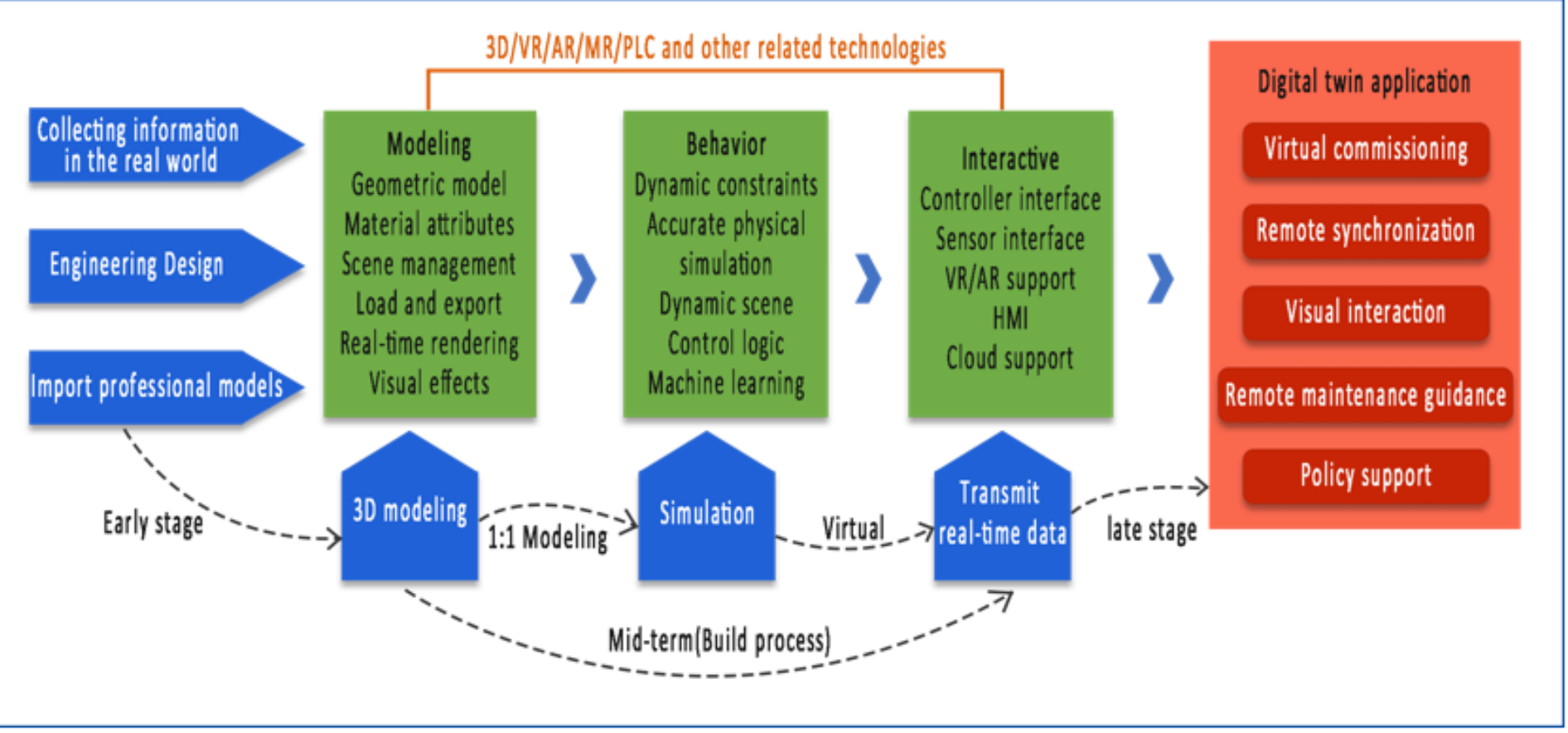

\section{Figure 2}

The digital twin's structure 


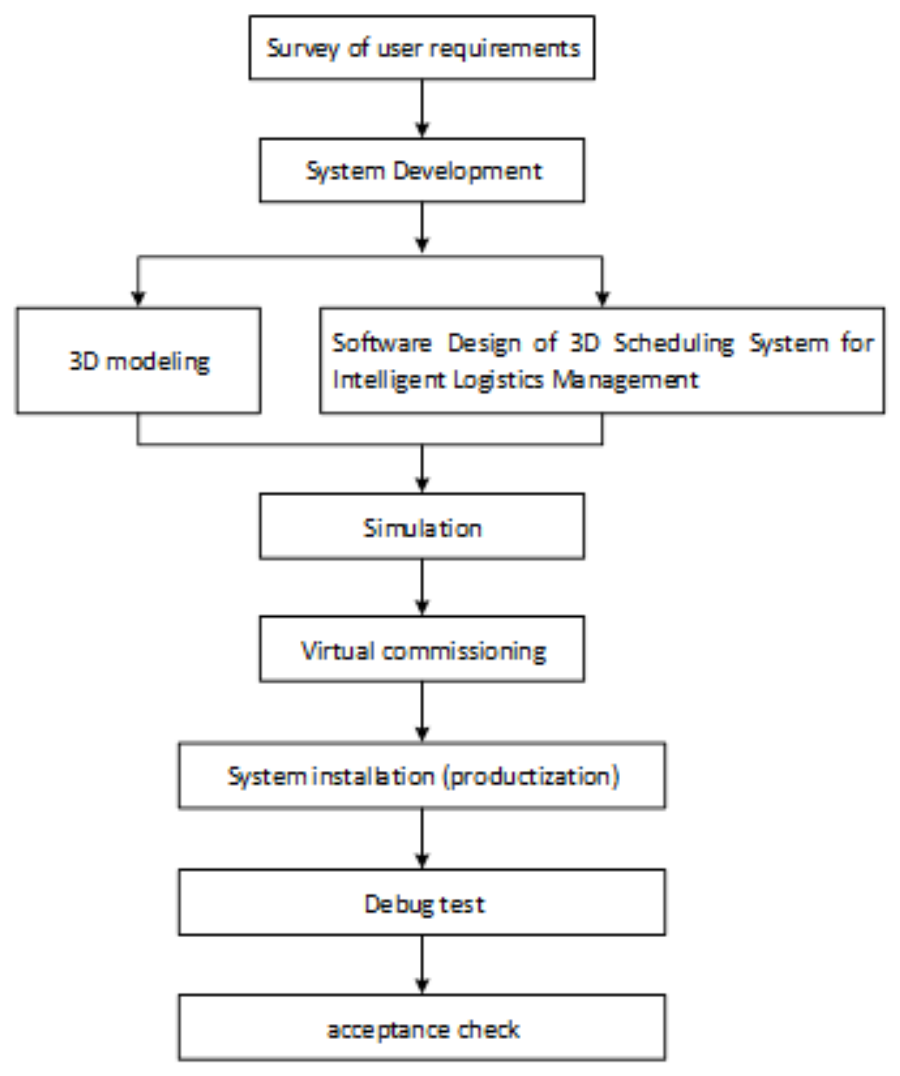

\section{Figure 3}

Case implementation steps 


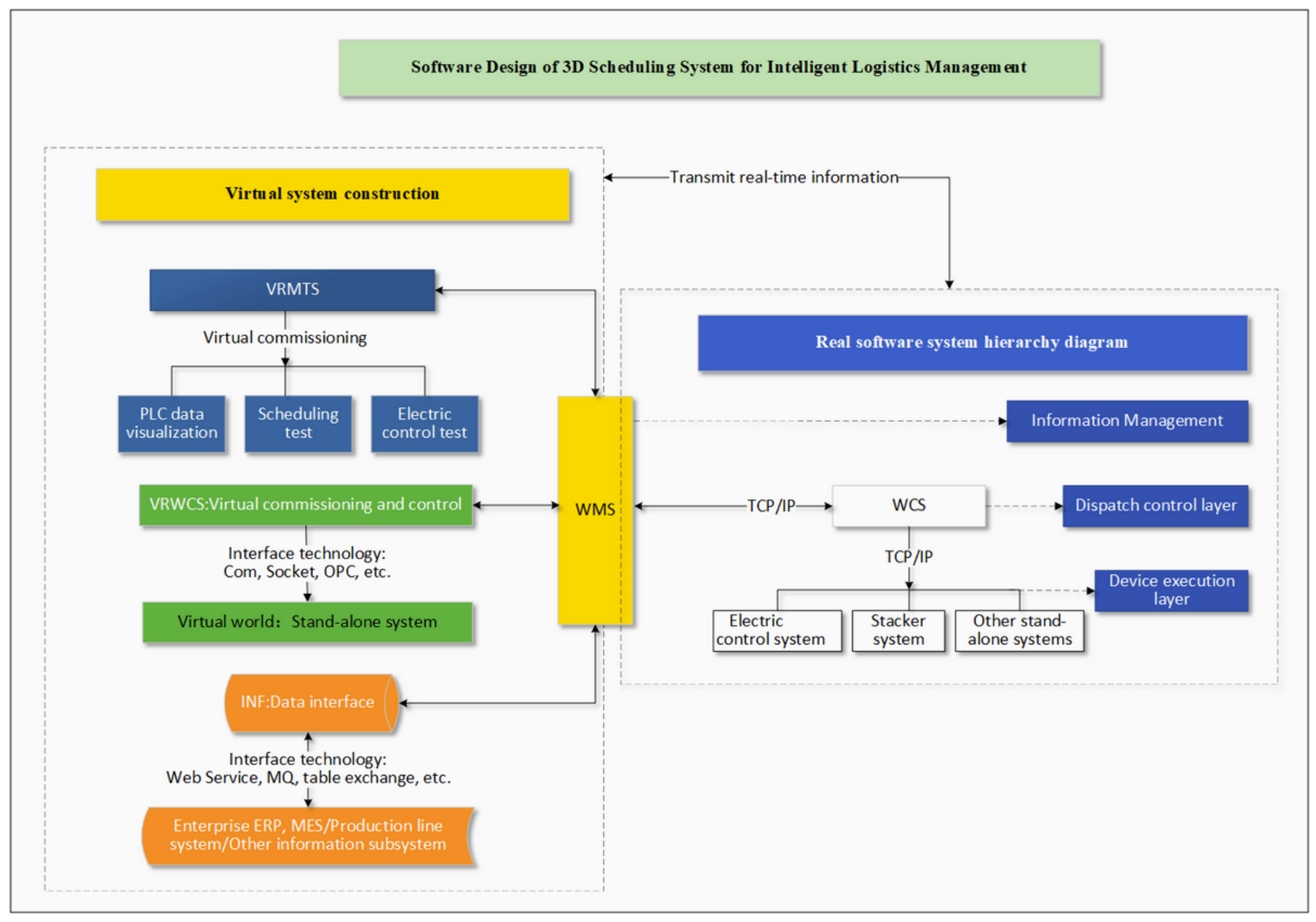

\section{Figure 4}

Design an intelligent logistics management 3D dispatch system 


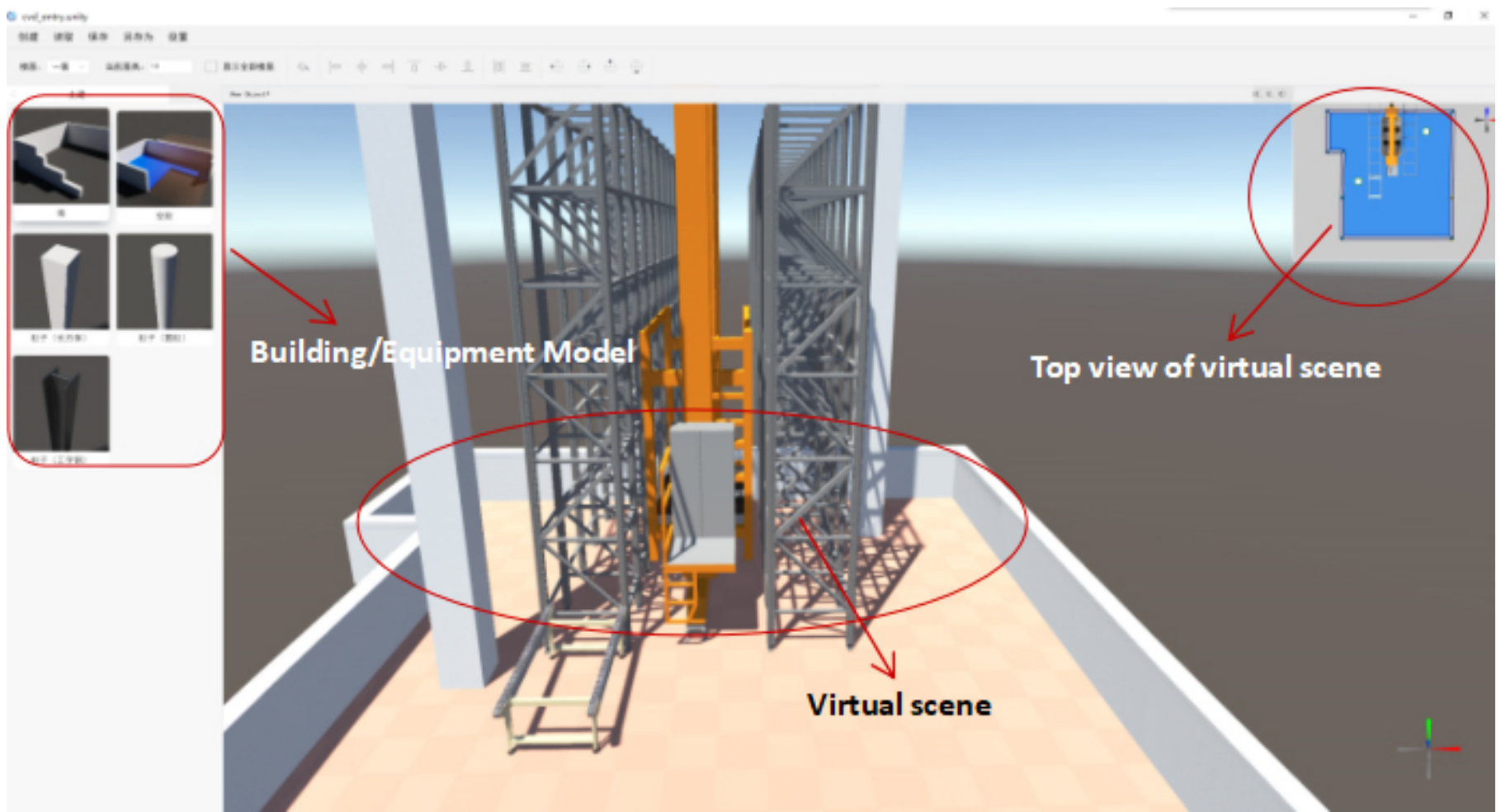

\section{Figure 5}

Virtual scene design software Fig 6. Compare the actual and virtual scenes

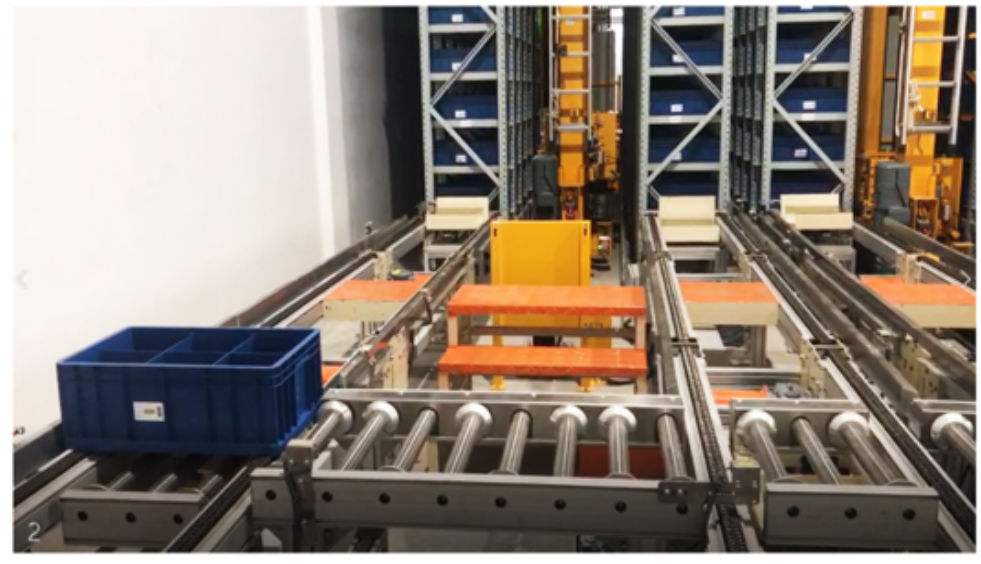

Real scene

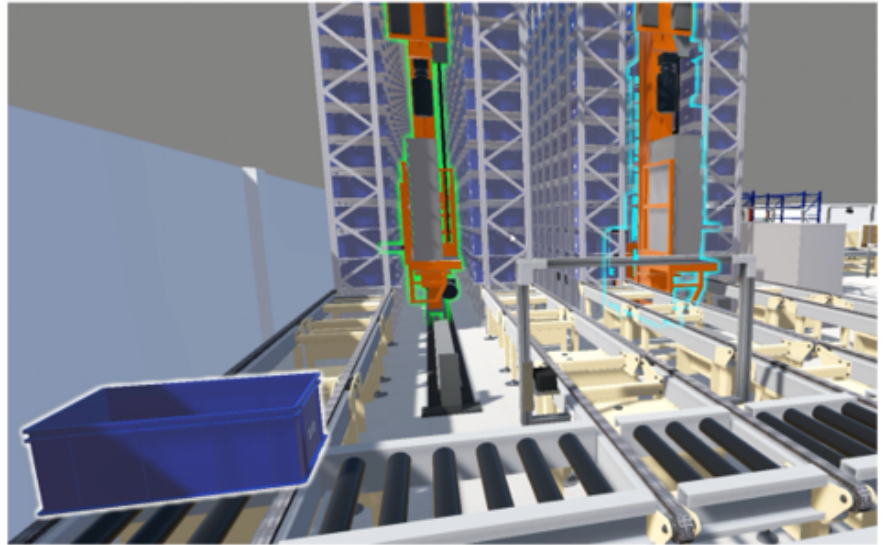

Virtual scene

Figure 6

Compare the actual and virtual scenes 


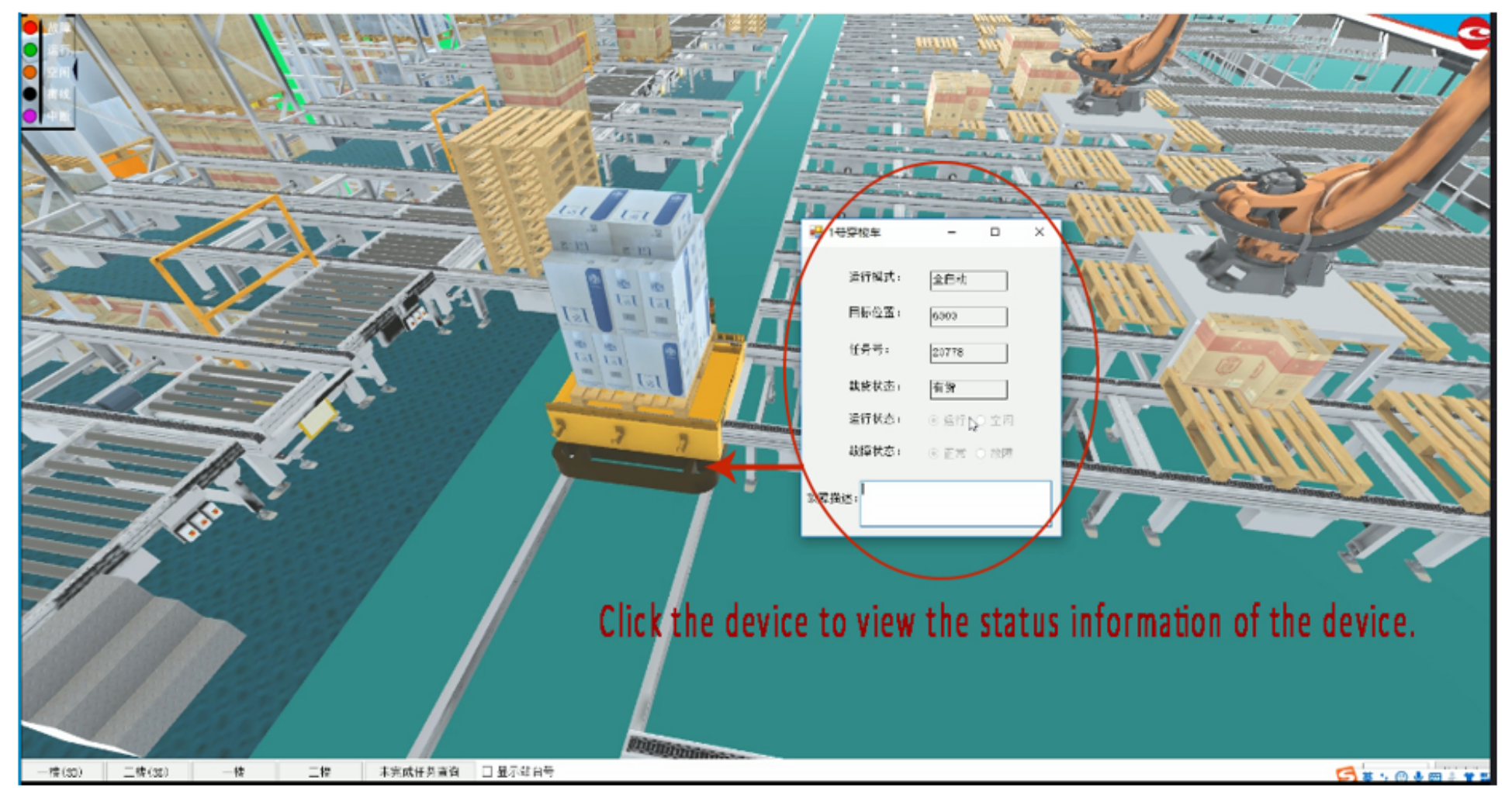

Figure 7

Demonstrate the 3D dispatch monitoring system's Kanban feature

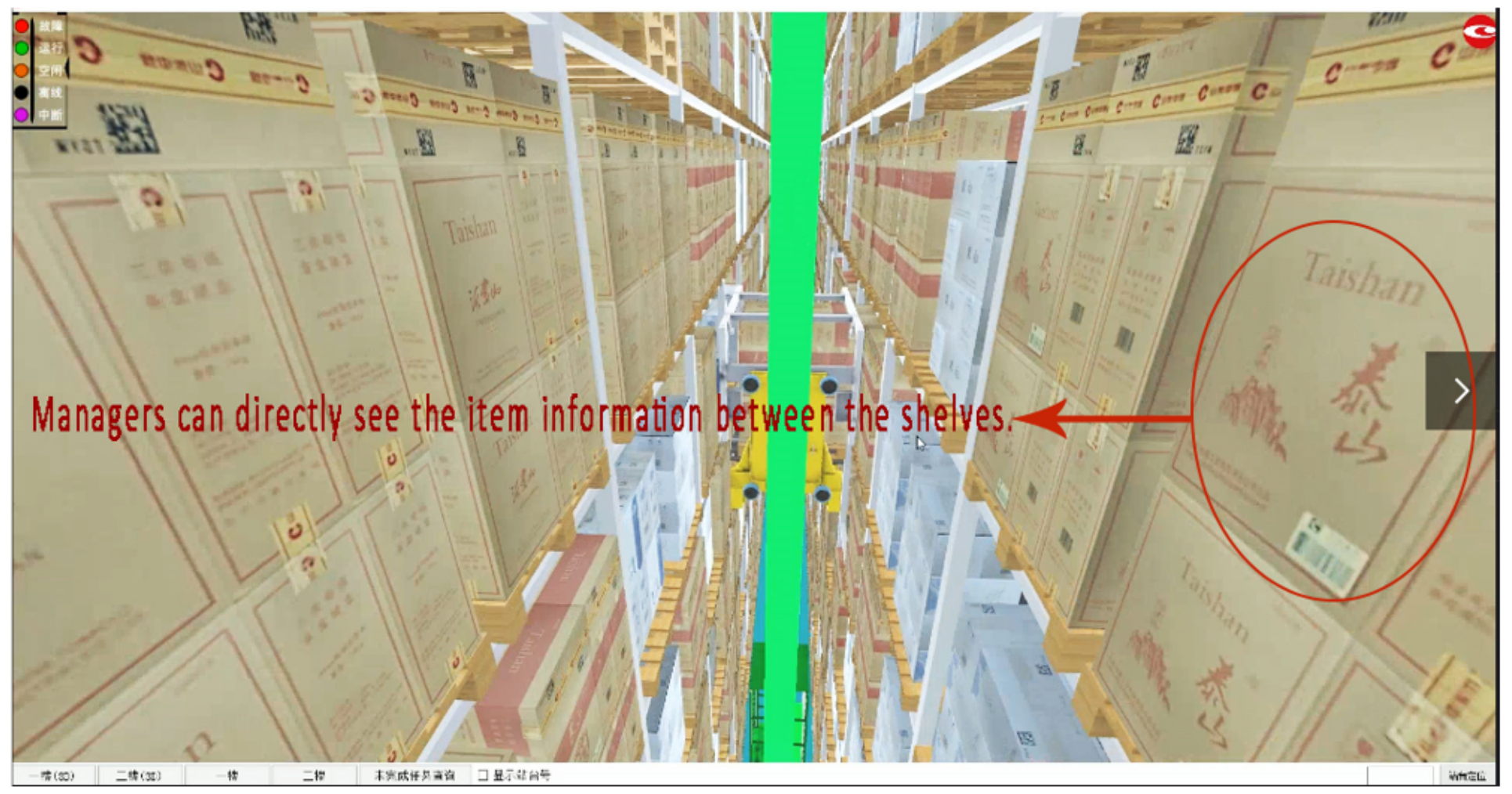

Figure 8 
Cargo area view

Page 24/24 